Journal of

Cardiology and Vascular Medicine

\title{
Advancing the Field of Regenerative Medicine
}

\section{Darcy L DiFede}

Director of Research, Interdisciplinary Stem Cell Institute, University of Miami School of Medicine, USA

${ }^{*}$ Corresponding author: Darcy L. DiFede, Director of Research, Interdisciplinary Stem Cell Institute, University of Miami School of Medicine, USA, E-mail: ddifede@med.miami.edu

Received Date: July 05, 2013, Accepted Date: August 15, 2013, Published Date: August 19, 2013

Citation: Darcy L. DiFede (2013) Advancing the Field of Regenerative Medicine. J Cardio Vasc Med 1:1.

Active clinical trials and ongoing preclinical work are advancing the development of cell-based therapies for heart failure and vascular disease. Clinical trial designs are taking on an increasingly sophisticated design in order to test and compare whole bone marrow and its leading constituents, as well as cardiac stem cells as components of novel cell based therapies. Important trial design considerations include adequate sample size, patient population, and appropriate endpoint selection. There are several key studies that have advanced the field notably: The following European trial testing improved ventricular remodeling as reported by Vroteovec et al.[1] Effects Intracoronary Stem Cell Transplantation in Patients With Dilated Cardiomyopathy; suggested improvement in left ventricular function and clinical status of patients with CD34+ cell therapy1.US publications of recent findings include the Poseidon Randomized Trial by Hare et al. [2] Comparison of Allogeneic vs Autologous Bone Marrow-Derived Mesenchymal Stem Cells Delivered by Transendocardial Injection in Patients With Ischemic Cardiomyopathy2. The SCIPIO trial by Bolli et al. [3] rep-

\section{References}

1) Bojan Vrtovec, Gregor Poglajen, Matjaz Sever, Luka Lezaic, Dragoslav Domanovic, et al. (2011) Effects of Intracoronary Stem Cell Transplantation in Patients With Dilated Cardiomyopathy; Journal of Cardiac Failure 17: 04 .

2) Hare JM, Fishman JE, Gerstenblith G, DiFede Velazquez DL, Zambrano JP, et al. (2012)Comparison of allogeneic vs autologous bone marrow-derived mesenchymal stem cells delivered by transendocardial injection in patients with ischemic cardiomyopathy: the POSEIDON randomized trial. JAMA 308:2369-2379.

3) Bolli R, Chugh AR, D'Amario D, Loughran JH, Stoddard MF, et al. (2011) Cardiac stem cells in patients with ischaemic cardiomyopathy (SCIPIO): initial results of a randomised phase 1 trial. Lancet. 378:1847-1857. resents a first in man trial of cardiac specific stem cells:Stem Cell Infusion in Patients With Ischemic Cardiomyopathy, A Phase I Randomized, Open-label Trial of CSCs in Patients With Post infarction LV Dysfunction Who Underwent Coronary Bypass Surgery, steered away from the traditional bone marrow source and targeted the heart itself to cultivate cardiac c-kit cells3.Vroteovec and Hare utilized the bone marrow and its derivatives for their trials. Collectively, these studies illustrate a favorable improvement inpatients' functional capacity, quality of life and ventricular remodeling.

Researchers continue to move toward more provocative strategies in order to conduct stronger, more robust clinical trials in an effort to identify the best cell type and the safest and most advantageous cell delivery method. In this regard several phase III trials are now underway or are being planned. This forward progress holds great promise for the new field of regenerative medicine for adverse heart conditions and other diseases. 